\title{
Cyclooxygenase-2 inhibition decreases primary and metastatic tumor burden in a murine model of orthotopic lung adenocarcinoma
}

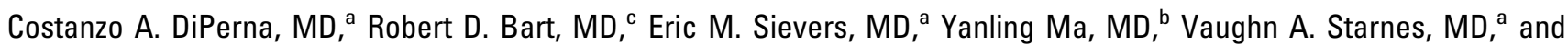
Ross M. Bremner, MD, $\mathrm{PhD}^{\mathrm{c}}$

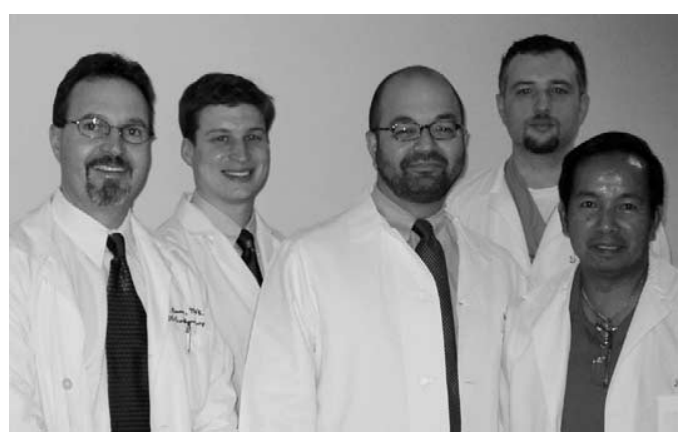

Hastings Thoracic Oncology Laboratory: Drs Bremner, Sievers, Bart, and DiPerna and Mr Salazar
Objective: To assess cyclooxygenase- 2 inhibition on primary tumor and mediastinal metastases in a murine model of orthotopic lung adenocarcinoma.

Methods: Human lung adenocarcinoma cells (CRL5908, female nonsmoker with cyclooxygenase- 2 expression by Western blot) were implanted under direct visualization through the parietal pleura in the upper lobe of the left lung $\left(2 \times 10^{6}\right.$ cells/animal $)$ of SCID mice. Mice were randomly assigned to 2 groups, either untreated $(n=62)$ or celecoxibtreated $(n=60)$. Celecoxib, a selective cyclooxygenase- 2 antagonist, was solubilized in the animals' drink ( $25 \mathrm{mg} / \mathrm{kg}$ per day). Mice were arbitrarily killed at 1,2,3, and 4 weeks. A blinded observer assessed primary tumor volume and metastatic disease grossly and histologically.

Results: Gross metastatic lymph nodes were present at 3 weeks in none of $15(0 \%)$ treated and 12 of $15(80.0 \%)$ untreated animals $(P<.0001)$. Mean primary tumor volumes at 3 weeks for treated mice were $7.9 \pm 10.0 \mathrm{~mm}^{3}$ and for untreated mice were $533.1 \pm 453.6 \mathrm{~mm}^{3}$ (mean $\pm \mathrm{SD}, P<.0001$ ). Gross metastatic lymph nodes were present at 4 weeks in 3 of $15(20 \%)$ treated and 17 of $17(100 \%)$ untreated animals $(P<.0001)$. Mean primary tumor volumes at 4 weeks for treated mice were $37.1 \pm 46.2 \mathrm{~mm}^{3}$ and for untreated mice were $809.6 \pm 1226.4 \mathrm{~mm}^{3}$ (mean $\pm \mathrm{SD}, P<.0001$ ). Mean blood levels of celecoxib in treated mice were $236.8 \pm 34.2 \mathrm{ng} / \mathrm{mL}($ mean $\pm \mathrm{SD})$.

Conclusions: Cyclooxygenase- 2 inhibition results in decreased primary and metastatic tumor burden in a murine model using human lung adenocarcinoma. Cyclooxygenase-2 inhibition has the potential to decrease tumor progression and metastases in patients with lung adenocarcinoma.

a grant from the Hastings Foundation, University of Southern California, Keck School of Medicine.

Read at the Twenty-seventh Annual Meeting of The Western Thoracic Surgical Association, Big Sky, Mont, June 19-22, 2002.

Address for reprints: Ross M. Bremner, $\mathrm{MD}, \mathrm{PhD}$, Department of Cardiothoracic Surgery, Keck School of Medicine, 1510 San Pablo St, Suite 415, Los Angeles, CA 90033(E-mail: rbremner@surgery.usc.edu).

J Thorac Cardiovasc Surg 2003;126: 1129-33

Copyright (C) 2003 by The American Association for Thoracic Surgery

$0022-5223 / 2003 \$ 30.00+0$

doi:10.1016/S0022-5223(03)00790-6

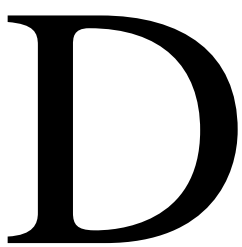

espite timely detection and "curative resection" for early-stage lung cancer, 5-year survival remains at $60 \%{ }^{1}$ In many survivors recurrence will take the form of distant disease, implying the presence of micrometastases at the time of surgery. ${ }^{2-4}$ Adjuvant chemotherapy has not dramatically improved overall survival. ${ }^{1}$ This shortcoming stems from chemotherapy protocols developed without adequate understanding of functional biologic differences between histologically similar lung cancers. A necessity exists to subdivide lung cancers on the basis of genetic and biochemical, not histologic, differences. ${ }^{3,5}$ The knowledge that allows us to categorize lung cancers biologically will give us the insight necessary to develop more effective targeted therapies.

Cyclooxygenase enzymes convert arachidonic acid to prostaglandins. Cyclooxygenase- 1 is the constitutive isoform and cyclooxygenase-2 (COX-2) is the induc- 
ible isoform. COX-2 is overexpressed in human adenocarcinomas including colon, lung, breast, bladder, pancreas, and uterus. ${ }^{6}$ Although its specific role in carcinogenesis is not defined, the presence of COX-2 is believed to promote a metastatic phenotype. Non-small cell lung cancer cells transfected with human COX-2 cDNA demonstrated an enhanced invasive capacity compared with control cells. ${ }^{7}$ Recent literature demonstrates a correlation between COX-2 expression and prognosis, where increased expression of COX-2 is associated with a poorer prognosis from lung adenocarcinoma. ${ }^{8,9}$

An in vitro study using colorectal cancer cells found etodolac, a COX-2 inhibitor, exerted cytotoxic effects and suppressed the invasive property of these cancer cells. ${ }^{10}$ Using mice subjected to injection of a murine colon cancer cell line overexpressing COX-2, Tomozawa and colleagues ${ }^{11}$ found a significant reduction in metastatic lung nodules in animals treated with a COX-2 inhibitor. Although the exact mechanisms remain unclear, the inhibition of COX-2 appears to attenuate, if not prevent, carcinogenesis or metastatic tumor progression. The aim of this study is to assess COX-2 inhibition on primary tumor growth and mediastinal metastases in a murine model of orthotopic lung cancer expressing COX-2.

\section{Methods}

\section{Cell Culture}

Human female lung adenocarcinoma cells expressing COX-2 by Western blot (CRL5908, female nonsmoker; American Type Culture Collection, Manassas, Va) were cultured in media (Roswell Park Memorial Institute [RPMI] medium 1640; 10\% fetal bovine serum [FBS]) until $90 \%$ confluent. Cells were trypsinized, washed, centrifuged, and resuspended to a concentration of $2 \times 10^{6}$ cells per $25 \mu \mathrm{L}$ in RPMI 1640 (cell passage $35 \pm 3$ ). Cell viability before and after injections was greater than 94\% (trypan blue stain).

\section{Animal Model}

Animal study was approved by the University of Southern California Institutional Animal Care and Use Committee. All animals received humane care in compliance with the "Guide for the Care and Use of Laboratory Animals" published by the National Institutes of Health.

Six-week-old mice with severe combined immunodeficiency (SCID bg male mice; Harlan Sprague Dawley, Inc, Indianapolis, Ind) were housed in polycarbonate cages ( 5 per cage) in a room lit for 12 hours each day and maintained at $27^{\circ} \mathrm{C}$ for 2 days before injection. Teklad (4\%) diet (Harlan Teklad, Madison, Wis) and tap water were provided ad libitum. Mice were randomly assigned into 2 groups, untreated $(n=60)$ or celecoxib treated $(n=62)$. Celecoxib, a selective COX-2 antagonist, was solubilized in the animals' drink to provide $25 \mathrm{mg} / \mathrm{kg}$ of drug per day. ${ }^{12-14}$ Administration began 1 day before tumor cell implantation and continued until the animals were killed. Mice were anesthetized by titrating isoflurane inhalant. A 1-cm subscapular incision allowed left lung visualization through intercostal muscles and pleura. Cancer cells were injected ( $25 \mu \mathrm{L}$ with $2.0 \times 10^{6}$ cells; 27 -gauge needle) into the left upper lobe at the fourth intercostal space. The incision was closed with 4-0 chromic suture and mice were allowed to recover. Mice were arbitrarily selected and killed at 1, 2, 3, and 4 weeks (n $=30 /$ week with 15 each in treated and untreated, except 4 weeks untreated $=17$ ) after implantation. All treated animals survived until killed, whereas 2 untreated animals died, 1 at day 24 and 1 at day 26. Before death, blood samples were obtained for celecoxib assay (Pharmacia, St Louis, Mo). At necropsy, a blinded observer assessed the presence of mediastinal lymph nodes and measured the primary tumor volume. Primary tumors and mediastinal nodes were snap-frozen in a beaker of 2-isopropanol on Dry Ice $\left(-18^{\circ} \mathrm{C}\right)$.

\section{Histology}

Frozen sectioning of primary tumors and lymph nodes was performed (4- $\mu \mathrm{m}$ sections on polylysine-coated slides). Sections were sequentially blocked for endogenous peroxidase $\left(3 \% \mathrm{H}_{2} \mathrm{O}_{2}\right.$ in methanol) and nonspecific protein binding $[1 \%$ bovine serum albumin [BSA] in phosphate-buffered saline soltuion (PBS)]. All tissue sections, excluding negative controls but including positive controls (breast adenocarcinoma), were incubated overnight at $4^{\circ} \mathrm{C}$ in the presence of COX-2 goat anti-rat polyclonal antisera (Alpha Diagnostic Intl, San Antonio, Tex). Subsequently, isoform-specific polyclonal anti-goat antisera (DAKO Corporation, Carpinteria, Calif) were diluted 1:100 in PBS for all sections. Immunoreactive complexes were detected using diaminobenzidine (DAB, Sigma Chemical, St Louis, Mo). Slides were counterstained with aqueous hematoxylin, mounted in crystal solution (Biomeda, Foster City, Calif), and coverslipped.

\section{Statistical Methods}

The 2-sided Fisher exact test was used to evaluate the statistical significance of the presence of lymph nodes between treated and untreated mice. The difference of mean values between treated and untreated mouse tumor volumes was evaluated by the MannWhitney $U$ test. Two-factor analysis of variance was used to study the effect of time and study group on tumor volume. SPSS (version 11.0, SPSS Inc, Chicago, Ill) statistical software was used for statistical testing.

\section{Results}

At 1 week, small left lung upper lobe adenocarcinoma nodules were present in all treated 15/15 (100\%) and untreated 15/15 (100\%) animals. At 2 weeks, all untreated animals exhibited primary tumor growth with histologic lymphatic invasion in 15 of 15 (100\%). Gross metastatic lymph nodes were present at 3 weeks in none of $15(0 \%)$ treated and 12 of $15(80.0 \%)$ untreated animals $(P<.0001$; 2-sided Fisher exact test; Figure 1). Mean primary tumor volumes from all 4 weeks are graphed (Figure 2). Mean primary tumor volumes at 3 weeks for treated mice were 7.9 $\pm 10.0 \mathrm{~mm}^{3}$ and for untreated mice were $533.1 \pm 453.6$ $\mathrm{mm}^{3}$ (mean $\pm \mathrm{SD}, P<.0001$; Mann-Whitney $U$ test). A representative gross comparison of treated and untreated tumors is shown in Figure 3. Gross metastatic lymph nodes 




Figure 1. Lymph nodes identified on gross examination (percent of mice with mediastinal lymph nodes) are compared between celecoxib-treated and untreated mice at each respective week. Weeks 3 and 4 were significant for differences between treated and untreated groups $(P<.0001 ; 2$-sided Fisher exact test).

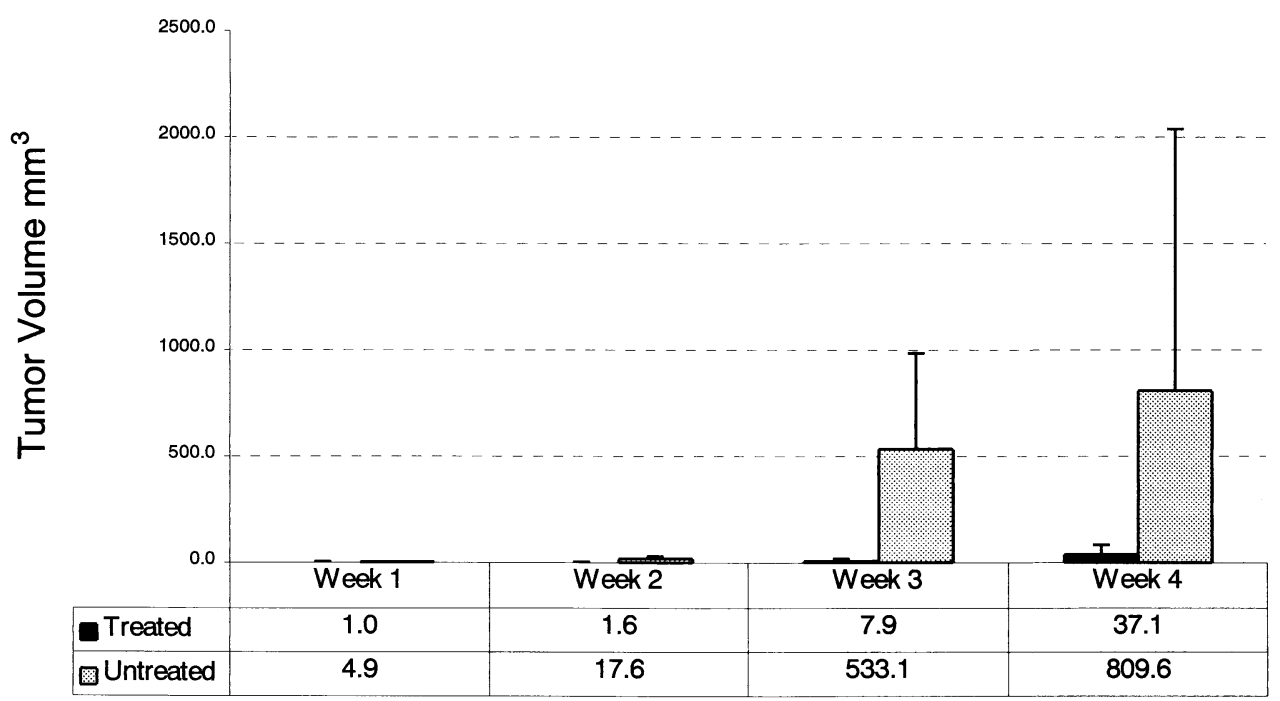

Figure 2. Primary tumor volumes (mean \pm SD) are compared between celecoxib-treated and untreated mice at each respective week. Weeks 3 and 4 were significant for differences between treated and untreated groups $(P$ $<$.0001; Mann-Whitney $U$ test).

were present at 4 weeks in 3 of $15(20 \%)$ treated and 17 of $17(100 \%)$ untreated animals $(P<.0001 ; 2$-sided Fisher exact test; Figure 1). Mean primary tumor volumes at 4 weeks for treated mice were $37.1 \pm 46.2 \mathrm{~mm}^{3}$ and for untreated mice were $809.6 \pm 1226.4 \mathrm{~mm}^{3}$ (mean $\pm \mathrm{SD}, P$ $<.0001$; Mann-Whitney $U$ test). Two-factor analysis of variance showed no statistically significant difference between week 3 and week 4 groups $(P=.3819)$, no statisti- cally significant interaction between week and experiment group $(P=.4788)$, and a statistically significant difference between treated and untreated groups $(P=.0004)$. A subset of pathologic specimens were randomly selected and underwent immunohistochemistry for COX-2 with hematoxylin counterstain. These specimens stained positive for the presence of COX-2. Mean blood levels of celecoxib at 3 and 4 weeks were $236.8 \pm 34.2 \mathrm{ng} / \mathrm{mL}$ (mean $\pm \mathrm{SD}$ ). Two of the 

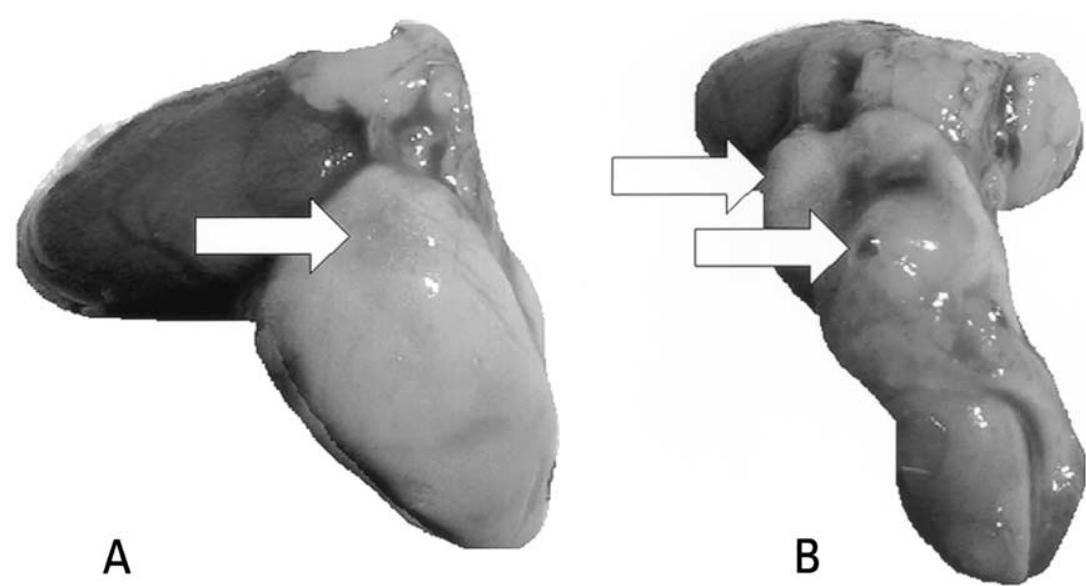

Figure 3. Three-week necropsy specimens consisting of left upper lung lobe, heart, and mediastinum with arrows indicating tumor in celecoxib-treated $(A)$ and untreated $(B)$ mice.

3 treated animals that developed mediastinal nodal metastases had the lowest blood levels for celecoxib.

\section{Discussion}

The persistent inability to improve 5-year survival from lung cancer combined with an evolving understanding of cellular biochemistry has provided the motivation and tools necessary for the development of novel biologic compounds directed at specific functional characteristics of the tumor. With improved understanding of signaling pathways and cellular biochemistry, new compounds can be developed and evaluated. The most prominent novel agents currently under study include epidermal growth factor receptor (EGFR) inhibitors, matrix metalloproteinases, E-cadherin promoters, and COX-2 inhibitors. Blocking EGFR inhibits tumor cell proliferation, leading to diminished tumor virulence. ${ }^{15}$ Inhibition of matrix metalloproteinases leads to decreased angiogenesis and stabilization of the extracellular matrix; stopping both processes results in decreased metastatic potential. ${ }^{16,17}$ Promotion of E-cadherin results in improved cellular adhesion, leading to a less metastatic phenotype. ${ }^{18-20}$ COX-2 inhibition promotes apoptosis, decreases angiogenesis, and diminishes metastases in many human cancers. ${ }^{14,21,22}$ COX-2 appears to be functionally related to many proteins including EGFR and E-cadherin. ${ }^{6}$

Both primary and metastatic disease were deterred by the COX-2 inhibitor celecoxib in the current study. Human lung adenocarcinoma tumor growth was found to be significantly less at 3 weeks of therapy and continued to be less through the termination of the study at 4 weeks. This was not the regression of preexisting tumor mass but the prevention of growth as compared with untreated animals. The evaluation of metastatic disease was limited to mediastinal lymph node disease. At 2 weeks, mice in both the treated and untreated groups had no lymph nodes discernable on gross examina- tion. As the mice progressed to 3 and 4 weeks after cancer cell injection, a difference was found between the treated and untreated groups. The mice treated with celecoxib had significantly fewer tumor-involved lymph nodes at both time points.

Blood levels of celecoxib reported in this study are comparable with those previously published. ${ }^{14,23}$ These levels correlate well with those attained in clinical use of celecoxib. ${ }^{24}$ An interesting observation is that the mice with the lowest levels of celecoxib were the individuals in which metastatic disease developed. Additional study is needed to define the strength of this potential correlation of an inverse relationship between celecoxib blood levels and cancer disease. ${ }^{25}$

The structure of this study initiated celecoxib treatment as a baseline shortly before injection of cancer cells. The treated mice developed primary tumor lesions and by 4 weeks $20 \%$ of these developed nodal lesions. Given this finding, it is unclear whether COX-2 inhibition is tumoristatic or tumoricidal. Altering some of the parameters in this study may allow an improved understanding of COX-2 and its inhibition. If celecoxib therapy is initiated at an interval after primary tumor is established, suppression of further tumor growth versus tumor regression may shed light on this question. The current study is limited to a 4-week interval. Subsequent studies extending the period of observation to 8 or 12 weeks or longer may aid in understanding the length of time tumors are responsive to COX-2 inhibitors. Another limitation is the fact that the cell line was chosen specifically because it expressed COX-2; use of adenocarcinoma cells that do not express COX-2 may yield different results.

COX-2 inhibitors are one of many potential novel chemotherapeutic agents. Although the role of COX-2 and pharmacologic inhibition in normal cells is understood, our current understanding does not pinpoint the specific mech- 
anism by which COX-2 inhibitors work in cancer. This study, along with others, provides evidence that COX-2 inhibitors may be effective in the treatment of lung cancer. Further studies are needed to determine the long-term efficacy of COX-2 inhibition, whether this provides permanent suppression, disease regression, and duration of therapy. These studies need to be performed in both animal models and humans. Ultimately, COX-2 inhibitors could be an adjuvant to standard chemotherapeutics, leading to increased survival for patients with lung cancer.

We thank Mr Robert Salazar and Dr Yangsun Jin for their expert technical assistance. Additionally, we thank Linda S. Chan, $\mathrm{PhD}$, for her review of the statistical analysis.

\section{References}

1. Mountain CF, Dresler CM. Regional lymph node classification for lung cancer staging. Chest. 1997;111:1718-23.

2. D'Amico TA, Massey M, Herndon JE, Moore MB, Harpole DH Jr. A biologic risk model for stage I lung cancer: immunohistochemical analysis of 408 patients with the use of ten molecular markers. $J$ Thorac Cardiovasc Surg. 1999;117:736-43.

3. D'Amico TA, Aloia TA, Moore MB, et al. Predicting the sites of metastases from lung cancer using molecular biologic markers. Ann Thorac Surg. 2001;72:1144-8.

4. Ahrendt SA, Yang SC, Wu L, et al. Molecular assessment of lymph nodes in patients with resected stage I non-small cell lung cancer: preliminary results of a prospective study. J Thorac Cardiovasc Surg. 2002;123:466-74.

5. D'Amico TA, Aloia TA, Moore MB, et al. Molecular biologic substaging of stage I lung cancer according to gender and histology. Ann Thorac Surg. 2000;69:882-6.

6. Fosslien E. Molecular pathology of cyclooxygenase-2 in neoplasia. Ann Clin Lab Sci. 2000;30:3-21.

7. Dohadwala M, Luo J, Zhu L, et al. Non-small cell lung cancer cyclooxygenase-2-dependent invasion is mediated by CD44. J Biol Chem. 2001;276:20809-12.

8. Achiwa H, Yatabe Y, Hida T, et al. Prognostic significance of elevated cyclooxygenase 2 expression in primary, resected lung adenocarcinomas. Clin Cancer Res. 1999;5:1001-5.

9. Khuri FR, Wu H, Lee JJ, et al. Cyclooxygenase-2 overexpression is a marker of poor prognosis in stage I non-small cell lung cancer. Clin Cancer Res. 2001;7:861-7.

10. Chen WS, Wei SJ, Liu JM, Hsiao M, Kou-Lin J, Yang WK. Tumor invasiveness and liver metastasis of colon cancer cells correlated with cyclooxygenase-2 (COX-2) expression and inhibited by a COX-2selective inhibitor, etodolac. Int J Cancer. 2001;91:894-9.
11. Tomozawa $\mathrm{S}$, Nagawa $\mathrm{H}$, Tsuno N, et al. Inhibition of haematogenous metastasis of colon cancer in mice by a selective COX-2 inhibitor, JTE-522. Br J Cancer. 1999;81:1274-9.

12. Reddy BS, Rao CV, Seibert K. Evaluation of cyclooxygenase-2 inhibitor for potential chemopreventive properties in colon carcinogenesis. Cancer Res. 1996;56:4566-9.

13. Grubbs CJ, Lubet RA, Koki AT, et al. Celecoxib inhibits N-butyl-N(4-hydroxybutyl)-nitrosamine-induced urinary bladder cancers in male B6D2F1 mice and female Fischer-344 rats. Cancer Res. 2000;60: 5599-602.

14. Masferrer JL, Leahy KM, Koki AT, et al. Antiangiogenic and antitumor activities of cyclooxygenase-2 inhibitors. Cancer Res. 2000;60: 1306-11.

15. Hidalgo M, Siu LL, Nemunaitis J, et al. Phase I and pharmacologic study of OSI-774, an epidermal growth factor receptor tyrosine kinase inhibitor, in patients with advanced solid malignancies. J Clin Oncol. 2001;19:3267-79.

16. Brooks PC, Stromblad S, Sanders LC, et al. Localization of matrix metalloproteinase MMP-2 to the surface of invasive cells by interaction with integrin alpha v beta 3. Cell. 1996;85:683-93.

17. Brooks PC, Silletti S, von Schalscha TL, Friedlander M, Cheresh DA. Disruption of angiogenesis by PEX, a noncatalytic metalloproteinase fragment with integrin binding activity. Cell. 1998;92:391-400.

18. Mayer B, Johnson JP, Leitl F, et al. E-cadherin expression in primary and metastatic gastric cancer: down-regulation correlates with cellular dedifferentiation and glandular disintegration. Cancer Res. 1993;53: 1690-5.

19. Doki Y, Shiozaki H, Tahara H, et al. Correlation between E-cadherin expression and invasiveness in vitro in a human esophageal cancer cell line. Cancer Res. 1993;53:3421-6.

20. Byers SW, Sommers CL, Hoxter B, Mercurio AM, Tozeren A. Role of E-cadherin in the response of tumor cell aggregates to lymphatic, venous and arterial flow: measurement of cell-cell adhesion strength. J Cell Sci. 1995;108:2053-64.

21. Chan TA, Morin PJ, Vogelstein B, Kinzler KW. Mechanisms underlying nonsteroidal antiinflammatory drug-mediated apoptosis. Proc Natl Acad Sci U S A. 1998;95:681-6.

22. Tsujii M, Kawano S, DuBois RN. Cyclooxygenase-2 expression in human colon cancer cells increases metastatic potential. Proc Natl Acad Sci U S A. 1997;94:3336-40.

23. Leahy KM, Ornberg RL, Wang Y, Zweifel BS, Koki AT, Masferrer JL. Cyclooxygenase-2 inhibition by celecoxib reduces proliferation and induces apoptosis in angiogenic endothelial cells in vivo. Cancer Res. 2002;62:625-31.

24. Steinbach G, Lynch PM, Phillips RK, et al. The effect of celecoxib, a cyclooxygenase-2 inhibitor, in familial adenomatous polyposis. N Engl J Med. 2000;342:1946-52.

25. Abou-Issa HM, Alshafie GA, Seibert K, Koki AT, Masferrer JL, Harris RE. Dose-response effects of the COX-2 inhibitor, celecoxib, on the chemoprevention of mammary carcinogenesis. Anticancer Res. 2001;21:3425-32. 